NBER WORKING PAPER SERIES

\title{
BENEFIT PLAN DESIGN AND PRESCRIPTION \\ DRUG UTILIZATION AMONG ASTHMATICS: \\ DO PATIENT COPAYMENTS MATTER?
}

\author{
William H. Crown \\ Ernst R. Berndt \\ Onur Baser \\ Stan N. Finkelstein \\ Whitney P. Witt \\ Jonathan Maguire \\ Kenan E. Haver \\ Working Paper 10062 \\ http://www.nber.org/papers/w10062 \\ NATIONAL BUREAU OF ECONOMIC RESEARCH \\ 1050 Massachusetts Avenue \\ Cambridge, MA 02138 \\ October 2003
}

Research support from the Ad Hoc Committee on the Economics of the Pharmaceutical Industry to Medstat and the Massachusetts Institute of Technology Program on the Pharmaceutical Industry is gratefully acknowledged. The opinions and views expressed in this paper are those only of the authors, and do not necessarily reflect those of the research sponsors or of the institutions with whom the authors are affiliated. The authors would like to thank Mark Pauly for his thoughtful comments. The views expressed herein are those of the authors and not necessarily those of the National Bureau of Economic Research.

(C2003 by William H. Crown, Ernst R. Berndt, Onur Baser, Stan N. Finkelstein, Whitney P. Witt, Jonathan Maguire, and Kenan E. Haver. All rights reserved. Short sections of text, not to exceed two paragraphs, may be quoted without explicit permission provided that full credit, including (C) notice, is given to the source. 
Benefit Plan Design and Prescription Drug Utilization Among Asthmatics:

Do Patient Copyaments Matter?

William H. Crown, Ernst R. Berndt, Onur Baser, Stan N. Finkelstein, Whitney P. Witt, Jonathan Maguire, and Kenan E. Haver

NBER Working Paper No. 10062

October 2003

JEL No. D12, I11, G22

\begin{abstract}
Objective: The ratio of controller to reliever medication use has been proposed as a measure of treatment quality for asthma patients. In this study we examine the effects of plan level mean out-ofpocket asthma medication patient copayments and other features of benefit plan design on the use of controller medications alone, controller and reliever medications (combination therapy), and reliever medications alone.
\end{abstract}

Methods: 1995-2000 MarketScan ${ }^{\text {TM }}$ claims data were used to construct plan-level out-of-pocket copayment and physician/practice prescriber preference variables for asthma medications. Separate multinomial logit models were estimated for patients in fee-for-service (FFS) and non-FFS plans relating benefit plan design features, physician/practice prescribing preferences, patient demographics, patient comorbidities and county-level income variables to patient-level asthma treatment patterns.

Results: We find that the controller reliever ratio rose steadily over 1995-2000, along with out-ofpocket payments for asthma medications, which rose more for controllers than for relievers. However, after controlling for other variables, plan level mean out-of-pocket copayments were not found to have a statistically significant influence upon patient-level asthma treatment patterns. On the other hand, physician practice prescribing patterns strongly influenced patient level treatment patterns.

Conclusions: There is no strong statistical evidence that higher levels of out-of-pocket copayments for prescription drugs influence asthma treatment patterns. However, physician/practice prescribing preferences influence patient treatment.

William H. Crown

Medstat

Ernst R. Berndt

Sloan School of Management

MIT, E52-452

50 Memorial Drive

Cambridge, MA 02142

and NBER

eberndt@mit.edu

Onur Baser

Medstat
Stan N. Finkelstein

MIT, Sloan School of Managment

Whitney P. Witt

Northwestern University

School of Medicine

Jonathan Maguire

Medstat

Kenan E. Haver

Department of Pulmonary Medicine

Massachusetts General Hospital 


\title{
BENEFIT PLAN DESIGN AND PRESCRIPTION DRUG UTILIZATION AMONG ASTHMATICS: DO PATIENT COPAYMENTS MATTER?*
}

\author{
William H. Crown, Ernst R. Berndt, Onur Baser, Stan N. Finkelstein, Whitney P. Witt, \\ Jon Maguire and Kenan E. Haver
}

\section{INTRODUCTION}

It has long been known that tradeoffs exist between the gains from pooling across individuals to insure against catastrophic medical expenditures, and the efficiency losses from the moral hazard effects that arise due to the implicit marginal subsidies to health services utilization that occur under conventional medical insurance plans. ${ }^{1}$ The existence of this tradeoff suggests that, given preferences and costs, there may be an optimal amount of coinsurance. Using data from the RAND Health Insurance Experiment in the 1980s, Manning and Marquis [1996] have estimated that with an $\$ 8000$ cap on total expenditures, the optimal coinsurance rate would have been about $50 \% .^{2}$

Although coinsurance rates for office visits, emergency room, inpatient hospitalization and prescription drug services were set to be equal in the design of the RAND Health Insurance Experiment, in practice currently in the U.S. coinsurance and, more commonly, patient copayment amounts differ considerably among the different categories of health care services. ${ }^{3}$

Within the last decade considerable controversy has arisen involving the design of prescription drug benefits in health insurance plans. This controversy reflects in part the fact that prescription drugs have become an increasingly important component of health care costs, rising sharply from $5.6 \%$ in 1980 to $9.7 \%$ in $2000 .{ }^{4}$ Continuing a recent pattern, in 2001 total prescription drug expenditures in the U.S. increased by about $17 \% .^{5}$ In levels, the $\$ 172.8$ billion implied an average of about $\$ 600$ per capita, although the underlying distribution is highly skewed.

Managed care organizations, and the employers with whom they contract, have attempted to control rising prescription drug costs by changing cost sharing provisions, seeking to steer use 
to preferred drugs on the insurer's list of approved medications ("formularies"). ${ }^{6}$ Already in the early and mid-1990s, plans began experimenting with two-tier copayment schemes, in which a low patient copay (say, \$5) was assessed for a generic (first tier) drug, and a somewhat higher but still modest copay (say, \$10) was assessed for (second tier) branded drugs; in some rare cases, physicians needed prior authorization from the payer before being granted permission to prescribe particularly costly medications.

After seeing continued increases in their prescription drug costs, in the mid and late 1990s some plans began implementing less generous three-tier copay schemes. A typical threetier plan design of several years ago consisted of a $\$ 5$ copay for a first tier generic drug, a $\$ 10$ copay for a "preferred" branded drug within a given therapeutic class (the second tier); and a heftier \$25 copay for the "non-preferred" branded third tier drugs within the therapeutic class. Many plans also had a second, more generous three-tier system for mail order pharmacy prescriptions.

Use of the three-tier copayment designs created incentives not only for insurees to shift toward increased use of the less costly medications, but it also gave insurance plans and payers increased bargaining power with pharmaceutical companies by allowing them to threaten to banish their branded products to the third tier, unless drug manufacturers offered the payer substantial discounts or rebates. ${ }^{7}$

Frustrated again by continued increases in prescription drug spending, more recently many plans have increased the levels of prescription drug copayments at all three tiers, with the third tier copayment as high as $\$ 40$ or $\$ 50$ per prescription, while other plans have turned to coinsurance rather than copayment designs. According to one source, in 2000 the average patient retail copayment for a generic first tier drug was $\$ 7.17$, that for preferred brands in the second tier was $\$ 14.14$, while that for all other nonpreferred brands on the third tier was $\$ 27.35$. $^{8}$

The increased use of multi-tier copayment design mechanisms for prescription drugs raises at least two sets of important issues: (i) do variations in copay structures alter the level and composition of prescription drug utilization? Are they effective instruments in controlling 
prescription drug costs? ${ }^{9}$ Or instead do persistent physician prescribing patterns dominate, with copayment variations having only a negligible impact? And (ii), to the extent three-tier copays affect the level and composition of drug utilization, what are the associated health outcomes? Can copayment design mechanisms be used not only to control costs, but also to steer utilization to more medically appropriate uses of prescription drugs? ${ }^{10}$ In this paper, we examine the first question in detail, and although we discuss possibilities concerning the second, we leave it largely for future research. We also examine variation over time and among plans involving copayments for other medical services, such as physician office visits, emergency room treatments, and inpatient hospitalizations.

We address these issues using the therapeutic class of asthma medications as a case study. As described in further detail below, asthma drugs can be envisaged as being primarily "reliever" medications (used to relieve symptoms in an acute asthmatic exacerbation -- an asthma "attack"), or as being primarily "controller" medications (used to control pulmonary inflammation and prevent an "attack"). For some time now, health care officials have argued that the appropriate use of controller medications can result in reduced outpatient office visits, emergency room treatments and inpatient hospitalizations. ${ }^{11}$ While the optimal ratio of asthma controller to reliever drug utilization is difficult to quantify precisely (and likely is patient idiosyncratic), it is widely believed that in most cases increases in the controller/reliever ratio are beneficial, both in terms of economic and medical considerations. ${ }^{12}$ Interestingly, a recent historical overview of trends in asthma pharmacotherapy between 1978 and 2002 by Stafford et al. [2002] suggests that particularly in the last decade, the controller/reliever ratio has increased while the number of asthma-related office visits has stabilized or declined.

Before proceeding with a discussion of hypotheses to be tested, underlying data and econometric methods, we first digress and provide some medical background on asthma and its treatment. 


\section{II. $\quad$ BACKGROUND ON ASTHMA AND ITS TREATMENT}

Asthma is a chronic disease characterized by inflammation of the airways and constricted bronchial tubes. Asthma affects about six percent of the population and is the third most common chronic condition among children. Although death from asthma is fairly unusual, morbidity from the condition is common. Since 1991, when consensus guidelines on the treatment of asthma were first released by the National Asthma Education Program [1991], clinicians have encouraged the use of maintenance therapy, typically using inhaled corticosteriods to "control" inflammation and to reverse chronic airway obstruction and hyperreactivity. Other medications, particularly the short-acting beta-two agonist class of bronchodilators, are recommended to be reserved for "relief" of acute episodes of bronchospasm. ${ }^{13}$

A number of published articles have examined the benefits that have accrued as the preference of "controller" to "reliever" medications as maintenance therapy for asthma has gained acceptance. ${ }^{14}$ Some of these articles have attempted to correlate a particular metric, commonly called the "C/B ratio" (ratio of inhaled corticosteroids to bronchodilators) with population-wide changes in survival and medical services utilization. ${ }^{15}$ Greater use of inhaled corticosteriods relative to bronchodilators has been reported to be associated with lower mortality rates and less frequent use of emergency room, inpatient and outpatient services in the care of patients with asthma. ${ }^{16}$

\section{III. $\quad$ HYPOTHESIS TO BE TESTED/ASSESSED EMPIRICALLY}

We empirically assess the effects of several benefit plan design features on asthma treatment patterns. In particular, we test the hypothesis that higher controller/reliever copay ratios will be associated with reduced use of controller medications, other things being equal, and 
whether any effects differ by plan type: fee-for-service ("FFS") versus non-FFS plans. Finally, we examine whether physician practice prescribing patterns influence patient-level asthma treatment patterns and, if so, whether these effects differ between FFS and non-FFS plans.

\section{DATA SOURCES AND CONSTRUCTION OF VARIABLES}

The MarketScan ${ }^{\mathrm{TM}}$ private insurance database for 1995-2000 was used in this study. MarketScan ${ }^{\mathrm{TM}}$ is the largest database of its kind, containing detailed descriptions of inpatient, outpatient medical, and outpatient prescription drug services for approximately three million persons in 2000 who were covered by corporate-sponsored healthcare plans. These individuals' healthcare was provided under a variety of fee-for-service (FFS), fully capitated, and partially capitated health plans, including exclusive provider organizations, preferred provider organizations, point of service plans, indemnity plans, and health maintenance organizations.

Race, ethnicity, and income information were extracted from a different data set, the Bureau of Health Professions Area Resource File (ARF), a compendium of county-level information produced annually. The ARF data were then merged with the MEDSTAT analytic file by county.

Identification of asthma patients

Patients with evidence of asthma were selected from the intersection of the claims, encounter, enrollment, and pharmaceutical data files. Evidence of asthma was provided by searching the claims data during 1995-2000 for individuals meeting any of the following criteria:

- At least two outpatient claims with primary or secondary diagnoses of asthma; or

- At least one emergency room claim with primary diagnosis of asthma, and a drug 
transaction for an asthma drug 90 days prior or 7 days following emergency room claim; or at least one inpatient claim with a primary diagnosis of asthma; or

- A secondary diagnosis of asthma and a primary diagnosis of respiratory infection in an outpatient or inpatient claim; or at least one drug transaction for a(n): anti-inflammatory agent; oral anti-leukotrienes; long-acting bronchodilators; inhaled or oral short-acting betaagonists.

Patients with a diagnosis of chronic obstructive pulmonary disease (COPD), who had one or more diagnosis or procedure codes indicating pregnancy or delivery, or who were not continuously enrolled for 24 months, were excluded from our study group.

Measures

Socio-demographic characteristics. The sociodemographic characteristics included the: age of the head of the household; percent female; geographic region (Northeast, North Central, South, West, and unknown); member type, and year of entry into the study. In addition, several socio-demographic variables defined at the county level were merged with the patient-level data. These variables included racial composition (\%white, \%black, \%other), and income strata.

Plan Type. Fee-for service plans were defined as plans that did not have an incentive for patients to use a particular list of providers, including basic, major medical, and comprehensive health insurance coverage. The remaining plans, called non-FFS, were defined as plans that either required patients to choose from a list of providers or provided financial incentives to use a specific list of providers. Non-FFS plans included: exclusive provider organizations, health maintenance organizations, non-capitated point-of-service plans, preferred provider organizations, or capitated or partially-capitated point-of-service plans. 
Copayments. Copayments for outpatient pharmaceuticals were calculated by first stratifying all prescription drug claims by year, then by plan within year. Next, we calculated the average out-of-pocket patient copayments for asthma drugs by therapeutic class for each plan, as well as the ratio of mean controller copayments to mean reliever copayments. These plan level ratios were then attached to each patient's record within a given plan.

We also constructed variables for the average out of pocket copayments paid for outpatient physician visits, emergency room visits, and hospital stays. The average copayment captured the actual dollar amount that the patients paid out of pocket. Note that we use the term "copayment" to refer to any out-of-pocket payment by individuals for health care. This includes both traditional copayments (e.g., $\$ 5$ per office visit) as well as coinsurance (e.g., patient pays $20 \%$ of the bill).

Comorbidities. A number of asthma-related comorbidities were examined. These included allergic rhinitis, anxiety, depression, gastroesophageal reflux disease (GERD), and migraine. The number of unique three-digit ICD-9 codes (International Classification of Diseases, Ninth Revision) was used as a proxy for extent of overall medical and mental health comorbidities.

Charlson Index scores were generated to capture the level and burden of comorbidity. This index draws upon diagnostic information from ICD-9 codes and procedure codes, resulting in nineteen conditions that are weighted based on the adjusted risk of one-year mortality. The index score is the sum of the weights for all of a patient's conditions and ranges from one to six, with higher numbers indicating increased levels of comorbidity. ${ }^{17}$ The Charlson Index has been highly effective in predicting clinical outcomes and costs. ${ }^{18}$ Of particular importance for our research, a recent study by Sin and $\mathrm{Tu}$ [2001] found that high levels of co-morbidity, as 
measured by the Charlson Index, were strongly associated with the underuse of inhaled steroid therapy in elderly patients with asthma.

Utilization. Utilization of healthcare services or prescription drugs was captured through claims and encounters over the study period. For individuals, we examined the mean annualized number of emergency room visits, hospitalizations, hospital days, outpatient visits, and allergy/asthma specialist visits. Prescription drugs for treatment of persons with asthma were categorized as either "controller" or "reliever" medications. Controllers included: inhaled antiinflammatory agents, oral corticosteroids, oral anti-leukotrienes, and long-acting bronchodilators; relievers were defined as drugs categorized as anticholinergics or inhaled shortacting beta-agonists. Based on this dichotomy, a ratio of controller to relievers was constructed and interpreted as a measure of adequate management of asthma.

Costs. The analytic file contains patients with fee-for-service health plans and those with partially- or fully-capitated plans. However data on costs were not available for the capitated plans. Therefore the value of patients' service utilization under the capitated plan was priced and imputed using average payments from the MarketScan ${ }^{\text {TM }}$ FFS inpatient and outpatient services by region, year, and procedure.

\section{ECONOMETRIC METHODS}

Our econometric analysis proceeds in two steps, using a variant of the Lee [1983] multinomial logit selection model, as proposed by Bourguignon, Fournier and Gurgand [2001]: (i) we first model choice among three alternative drug treatments - only controller, only reliever, and combination controller-reliever, all on an annual basis. We employ as identifying instruments (variables affecting choice of drug treatment, but not total expenditures) plan copayment variables, and physician/provider prescribing composition. Then in (ii) we employ in 
least squares regressions of log total expenditures for each treatment arm, in addition to a usual set of covariates, the three "lambda selection terms" (conditional expectations of residuals from the three arms of the treatment selection model).

More specifically, to reduce the potential for endogeneity between plan level copayment variables and plan level controller/reliever ratios in the multivariate analyses, we utilize a discrete counterpart to the plan-level controller/reliever ratio examined in the descriptive analyses. In particular, we construct an annual patient-level dependent variable with three mutually exclusive categories: controller drug alone $(n=3903)$, a combination of a controller drug and a reliever drug $(n=11,427)$, and a reliever drug alone $(n=11,049)$. A likelihood ratio test was carried out to examine whether separate models were required for the FFS and non-FFS samples. Based upon the results of this test, we estimated separate multinomial logit models for the FFS and non-FFS subsamples. County-level income variables were appended to patient records to augment the medical claims. Robust standard errors were used to adjust for potential intra-county covariance among patients living in the same counties that may have been introduced by these variables. Hausman tests were then conducted to compare selectivitycorrected models with standard OLS models.

In terms of instruments, we construct two sets of identifying variables. Our first set is plan copayments. For each year and plan, we calculate mean copayment values for each class of drug, and then take the ratio of controller mean to reliever mean copayment. This plan-specific variable is utilized as a regressor in the multinomial drug treatment choice equations for each person year. A second set involves calculating, for each physician/provider tax identification number in the claims data, the proportion of patients obtaining controller only, reliever only, and combination treatment. In many cases this taxation ID covers a multi-physician medical 
practice, but in some cases it is unique to a single physician. Since the sum of these three percentages is $100 \%$ for each physician/provider practice, we delete one of the three percentages, but include two of them as regressors in the multinomial drug treatment model. We recognize that this still leaves room for some selectivity in the form of patients' choice of physician and choice of plan, but nonetheless believe that this method provides a reasonable first step in mitigating the effects of such selectivity. We also note that, in this paper we do not examine the implications of treatment patterns on components of subsequent health care utilization, although we do model total healthcare expenditures.

\section{DESCRIPTIVE RESULTS}

Based on the definitions of asthma episodes discussed above, we obtained a sample that included 44,926 patients in FFS plans and 18, 305 in non-FFS plans $(63,231$ patients in total).

Controller/Reliever Ratio. As shown in Figure 1, the controller/reliever ratio has been rising over time. Between 1995 and 1999, it increased by approximately 40\%, with more rapid increases in the two most recent years. The ratio is consistently higher for patients in FFS plans than for those in non-FFS plans and, since 1997, the rate of increase appears to be higher for the FFS plan beneficiaries than for those in non-FFS plans. However, irrespective of plan type, almost all plans had average controller/reliever ratios greater than one (plan-specific data not shown).

Patient Demographics. Table 1 reports the demographic characteristics of the sample, stratified by FFS and non-FFS plans. Patients in FFS plans had a mean age of 34 years compared to 27 years for non-FFS plans $(p<.001)$ and were more likely to be female $(57 \%$ versus $52 \%, \mathrm{p}<.001)$. Patients in FFS plans were also more likely than patients in non-FFS plans to be 
located in the North Central region ( $67 \%$ versus $9 \%, \mathrm{p}<.001)$, as well as more likely to receive their health care coverage as the employee rather than as the spouse or dependent ( $41 \%$ versus $37 \%, \mathrm{p}<.001)$.

County Race and Income. Substantial differences in racial distribution and mean income between FFS and non-FFS plans were evident from county-level U.S. Census data linked to the claims data. The mean household county income of patients covered by FFS plans $(\$ 27,001)$ was significantly lower than that for patients covered by non-FFS plans $(\$ 31,223)(\mathrm{p}<.001)$. Interestingly, the racial distribution of counties for patients covered by FFS plans was less likely to be white than that of non-FFS plans.

Health Status. As expected given possibilities for adverse selection, patients in FFS plans appear to be sicker than those in non-FFS plans. Table 2 documents that patients in FFS plans have higher numbers of major diagnostic categories, higher Charlson comorbidity scores and higher rates of comorbidities of allergic rhinitis, depression, gastrointestinal disorders, and migraine ( $<.001$ for all comparisons). The rate of comorbid anxiety was not statistically different between FFS and non-FFS plans $(\mathrm{p}=0.78)$. Qualitatively similar patterns were evident both for patients ages 4-11 and those ages 12-64, although differences were typically larger for adults than for children.

Copayments. Table 3 indicates that prescription drug copayments are significantly higher in non-FFS plans than in FFS plans, for both asthma medications and nonasthma medications. Across all drugs and all years (1995-2000) the average out of pocket copayment made by patients in non-FFS plans was $\$ 8.64$ compared to $\$ 5.20$ in FFS plans $(\mathrm{p}<.001)$. However, as shown in Figure 2, average controller/reliever copayment ratios were higher in FFS plans than in non-FFS plans, even as FFS plan beneficiaries had greater controller/reliever medication 
utilization ratios (see Figure 1). In both types of plans the controller/reliever copayment ratio has been rising over time along with the increased use of controller medications.

The mean copayments reported in Table 3 mask considerable variation in copayments over time and across plans. Figure 3 illustrates that out-of-pocket copayments for asthma medications have been consistently higher for patients in non-FFS plans compared to patients in FFS plans. Although both patients in both types of plans experienced significant jumps in outof-pocket copayments beginning in 1998, the gap between FFS and non-FFS plans appears to have narrowed. In addition to these time trends, there is high variation in copayment levels for specific drugs within year. For example, in 1999 copayments for fluticasone, an inhaled corticosteroid (a controller medication), varied from $\$ 2$ in one plan to $\$ 28$ in another plan. Similarly, 1999 copayments for albuterol, a short-acting beta agonist (a reliever medication, typically sold as a generic), ranged from $\$ 2$ to $\$ 12$ across plans.

Figure 4 reports the trend in the ratio of total payments (third party payor plus patient copayment) for controller versus reliever prescription drug claims, alongside the trend in the ratio of patient out-of-pocket copayments for controller vs. reliever medications. Both ratios show an upward trend, largely reflecting the increased use of controller medications. However, Figure 4 clearly indicates that between 1995 and 1999 the total payment ratio rose at a steeper rate than the copayment ratio. This suggests that, although large employers and health plans were using copayments to help manage rising prescription drug costs, at least between 1995 and 1999 they appeared to be absorbing proportionately more of the cost increase than they passed on to beneficiaries in the form of higher copayments. Put another way, the practice of medicine improved in the sense of both FFS and non-FFS beneficiaries increasing the controller/reliever 
utilization ratio, and while beneficiaries experienced increases in controller/reliever copayment ratios, third party payors bore an even larger increase in controller/reliever payments.

Average copayments for outpatient visits, emergency room visits, and inpatient visits also differed between non-FFS and FFS plans (Table 3). Although statistically significant, copayments for outpatient visits and emergency room visits were fairly similar across non-FFS and FFS plans. By contrast, copayments for inpatient stays were significantly and materially higher among patients covered by FFS plans than those covered by non-FFS plans $(\$ 16.12$ versus $\$ 2.78$, respectively, $\mathrm{p}<.001)$. Hence, while non-FFS plans had significantly higher copayment rates for prescription drugs relative to FFS plans, the opposite took place in terms of inpatient copayments.

Medication Use. Table 4 summarizes the medication use of asthma patients covered by non-FFS and FFS health plans. Patients covered by FFS plans have a higher ratio of controller to reliever medications than patients in non-FFS plans ( 1.49 versus $1.17, \mathrm{p}<.001)$, as well as a higher number of annualized asthma prescriptions (4.89 versus $4.17, \mathrm{p}<.001)$. With the exception of leukotriene modifiers (the most recent new therapeutic agents), patients in FFS plans have more days of therapy and higher units dispensed for each therapeutic class of asthma medication than patients in non-FFS plans ( $\mathrm{p}<.001$ for all comparisons). For leukotriene modifiers, days of therapy and units dispensed were higher for asthma patients covered by nonFFS plans $(\mathrm{p}<.001)$.

The most commonly prescribed asthma medications were the short acting beta agonists (SABAs). Patients in non-FFS plans were somewhat more likely than patients in FFS plans to be prescribed SABAs, oral steroids, and leukotriene modifiers; they were less likely to be prescribed bronchodilators, inhaled steroids, and anticholinergics ( $\mathrm{p}<.001$ for all comparisons). 
Health Care Utilization. Table 5 reports the non-prescription drug health care utilization of patients in non-FFS and FFS plans. For each measure-emergency room visits, hospitalizations, hospital days, and outpatient visits—annualized utilization was higher in FFS plans than in non-FFS plans ( $\mathrm{p}=0.09$ for all comparisons). Thus, despite higher controller/reliever medication ratios, health care utilization was higher in FFS plans than in nonFFS plans. However, this association is likely confounded by the greater average age and level of disease severity of patients covered by FFS plans (Table 2).

\section{ECONOMETRIC FINDINGS}

FFS Model. Table 6 reports the results of a multinomial logit model of the log odds of a patient receiving controller medication alone, or a controller and a reliever (combination therapy), relative to a reliever alone. Residents of the North Central region are significantly less likely to be treated with controllers alone or combination controllers-relievers than with relievers alone ( $\mathrm{p}$-values $<0.01$ ). Females were significantly less likely to receive a combination treatment rather than a solo reliever treatment. Adults were more likely to receive a controller alone, or a combination treatment (with the former being particularly large) than a reliever only treatment.

We also included county-level variables from the Census as proxies for the income of patients--variables not available directly from the claims. Being in the highest average income county $(>\$ 35 \mathrm{~K})$ significantly increased the odds of receiving a controller-only treatment, but had no significant effect on combination treatment, relative to reliever-only treatments. None of the other county characteristic income variables was statistically significant.

The presence of allergic rhinitis increased the odds of getting a controller alone or a combination therapy relative to reliever only therapy. Comorbidities of migraine or sinusitis had 
no significant impact on choice of drug therapy. Depression reduced the odds of getting controller alone therapy relative to reliever alone, but had no significant impact on combination therapy. Interestingly, the presence of an anxiety disorder increased the odds of getting a combination therapy ( $\mathrm{p}$-value $<0.02$ ), but had no significant impact on the probability of receiving either of the solo treatments. The number of unique 3-digit ICD-9 codes was positively associated with the log odds of getting a controller alone, or a controller plus reliever, and thereby was implicitly negatively associated with the log odds of getting a reliever only therapy.

The ratio of plan mean controller to mean reliever copay had no significant impact on drug treatment choice ( $\mathrm{p}$-values $>0.50)$. In results not shown, this lack of significance persisted when mean copays were entered separately in levels, or in various other forms. On the other hand, the medication ratios measuring provider prescribing preferences for controller alone $(\mathrm{p}$ value $<0.01$ ) or for combination treatment ( $p$-value $<0.01$ ) were positive, large and highly significant determinants for the probability of the patient receiving that therapy, relative to reliever only therapy. In terms of cross-effects, only provider prescribing preferences for combination therapy positively and significantly affected the probability of a patient receiving controller-only therapy; provider preferences for controller only therapy had no significant impact on the patient's probability of receiving combination treatment ( $\mathrm{p}$-value $=0.184)$. The chi-square test statistic for the null hypothesis that coefficient estimates on the copay and provider prescriber preference variables are simultaneously equal to zero indicate decisive rejection in both equations ( $\mathrm{p}$-values $<0.01$ ).

Non-FFS Model. Table 7 reports the results of the corresponding multinomial logit model for patients in non-FFS plans. Living in the West reduced the odds of receiving either 
controller alone or combination treatment relative to reliever alone therapy. Residents of the North Central region were more likely to receive combination treatment, but not controller only therapy, relative to controller alone treatment. As in the FFS case, females were significantly less likely to receive combination treatment, relative to reliever only, and adults were more likely to receive a controller alone or a combination therapy (with the former being particularly large), relative to reliever-only treatment. None of the county-level income variables from the Census was statistically significant.

The presence of allergic rhinitis significantly increased the odds of getting controller only or combination therapy relative to reliever only treatment; the impacts of other comorbidities were similar in this non-FFS regression to those in the FFS analysis. Higher numbers of unique 3-digit ICD-9 codes significantly increased the odds of getting a controller alone or combination therapy relative to reliever only treatment.

As with the FFS model, the ratio of plan mean controller to mean reliever copayment had no significant impact on the probability of receiving controller-only therapy, although it did have a positive and significant impact on the odds of receiving combination treatment. On the other hand, both medication percentages measuring provider prescribing preferences were highly significant determinants of the probability of a patient receiving the corresponding therapy; while these own effects were positive and significant, both cross-effects were not statistically significant. The chi-square test statistics for the null hypothesis that coefficients on the copay and provider prescriber preference variables simultaneously equal zero indicate decisive rejection in both equations ( $\mathrm{p}$-values $<0.01$ ).

Turning now to the log total expenditure regressions for FFS (Table 8) and non-FFS (Table 9) beneficiaries, we provide parameter estimates with and without the sample selectivity 
adjustments, for each of the three treatment arms. In the FFS regressions of Table 8, we first note that parameter estimates on the lambdas (conditional expected values of the residuals derived from each of multinomial logistic equations) are negative and statistically significant (all p-values $<0.001$ ). Not surprisingly, differences between the selectivity-adjusted and unadjusted parameter estimates are particularly large for those variables significantly affecting prescriber therapy in the first-state multinomial logit equations. For example, coefficient estimates on the adult variable in all three equations are much smaller in the selectivity-adjusted than in the unadjusted regressions; this also holds for the allergic rhinitis variable, where sign changes occur.

However, when a Hausman test is conducted to test whether the coefficient estimates differ significantly in the selectivity-adjusted and unadjusted OLS regressions with the FFS sample, the null hypothesis of parameter equality is not rejected; indeed, the test statistic is negative, a reflection of the fact that the difference in diagonal elements of the variancecovariance matrices can in given samples be negative, even though asymptotically they are positive in expectation.

In terms of the non-FFS sample (Table 9), results are qualitatively similar to those with the FFS population. In particular, estimates of the three lambdas are negative and significant in all three treatment equations ( $\mathrm{p}$-values ,0.001), with the exception of the reliever only equation where the negative estimate is not statistically significant. While two of the three Hausman test statistics on parameter equality in the selectivity-adjusted and unadjusted OLS regressions are positive, in all three cases the null hypothesis is not rejected. 


\section{DISCUSSION AND LIMITATIONS}

This study describes the patterns of medication use among patients with asthma, factors affecting the type of drug therapy prescribed these patients, and impacts on total healthcare expenditures, using a dataset encompassing more than 25,000 patient years of claims. The average controller/reliever ratios were found to be greater than one, both for members of nonFFS (1.17) and FFS (1.49) plans. Moreover, the controller/reliever medication ratio has been consistently rising over time, suggesting that the clinical practices it embodies reflects a considerable degree of acceptance of the consensus guidelines, and the supporting research literature.

Theoretically, holding other things equal, one would expect higher relative prices for controller to reliever medicines to be associated with a lower controller/reliever ratio. However, teasing this out of the data statistically is complex. Shifts in the composition of drugs in the controller and reliever classes over time, and changes in plan design, could cause the ratio of controller to reliever copays to either rise or fall over time. As shown in Figure 1, the controller/reliever medication ratio has been trending upward over time. However, after controlling for other variables we do not find a statistically significant relationship between outof-pocket copayments and asthma treatment patterns. Moreover, Figure 4 indicates that total payments (third party payor plus patient copay) have been rising more rapidly than copayments only, suggesting that health plans and large employers are reluctant to increase copayments for covered beneficiaries at the same rate that total payments have increased. In this sense and over 
this 1995-1999 time period, health plans and payors have contributed to greater diffusion of guideline-compatible treatments that favor increases in the controller/reliever ratio.

The observation that the prescribing of all classes of asthma medications (except leukotriene modifiers) was greater among members of FFS plans is generally consistent with the findings that these patients are "sicker" than their counterparts in non-FFS plans, as measured by the number of comorbid conditions and higher levels of health care utilization. Asthma patients covered by FFS health plans made more extensive use of all other types of health services we examined, including inpatient hospitalizations, use of emergency services and ambulatory visits.

The principal objective of this study has been to examine whether and how the characteristics of health plan coverage as part of the employee benefits affects the therapy selection decision among patients with asthma. The preponderance of clinical literature now suggests that patients with asthma experience more favorable clinical courses when they make regular use, often several times daily, of inhaled corticosteriods, leukotriene modifiers, and other medications that "control" inflammation and reversible airway disease. In the descriptive analysis, we found that the controller/reliever ratio continued to rise (and its increase even accelerated in recent years) despite rising medication copays. However, this apparent association between mean copayments at the plan level and plan-level controller/reliever ratios is potentially endogenous. For example, if mean copayments are higher for controller medications than reliever medications, growing use of controllers would result in a rising mean copayment ratio for controller-to-reliever medications. That is, at the plan level, the direction of influence between the controller-to-reliever copayments and the controller/reliever ratio could go in either direction, or even both ways. 
To reduce the endogeneity problem, we examined the effect of plan-level copayment variables on individual treatment choices. When we did so, no statistically significant association was found. It is possible that this lack of association resulted from an understatement of the size of out-of-pocket copayments. This understatement is due to the averaging of patient copays across asthma drugs and years at the plan level, an effort we undertook in order to reduce the number of degrees of freedom consumed by plan-, drug-, and year-specific copayments. Most of the large copayment increases have occurred since 1999. Plans that instituted very large copayment increases for certain asthma drugs may, indeed, have shifted asthma treatment patterns. However, in our analysis these more recent changes were aggregated with earlier experience of patients where copayment changes were not as common, nor as large. Thus, we expect that there is a downward bias in our estimate of the copayment effect that deserves further scrutiny. We have re-estimated our models using only 1998-2000 data, and while we obtained results on the copay variables that trended more toward becoming statistically significant, they were not significant at usual p-values. We suspect that these copay variables will become more significant as additional years of post-2000 data are added to the sample.

On the other hand, we found that provider prescribing patterns were strongly associated with patient treatment patterns, although the nature of this association differed somewhat for patients in FFS and non-FFS plans. We leave it for future research to assess whether, controlling for physician practice prescribing preferences, differences in copayment benefit design across plans serviced by the same physician practice result in statistically different treatment patterns. It is of course possible instead that physician practice effects are dominant regardless of the variation in the copayment benefit designs of the plans covering the patients 
they treat. Resolution of this issue will have very important implications for the effectiveness of plan design in controlling healthcare costs.

In addition to the specific statistical issues already discussed, the conclusions from our analysis should be viewed in light of the limitations common to most retrospective studies. In particular, although we have attempted to correct for selection bias associated with patients having higher versus lower controller to reliever ratios, other sources of selection bias may remain. For example, the MarketScan claims data used in the analysis lack clinical measures of symptom severity (e.g., FEV-1 values). In addition, missing data on within region location (e.g., rural, urban, suburban) could have introduced bias due to geographical variations in asthma treatment practice patterns.

Although future work is unlikely to be able to control for all sources of selection bias in retrospective database studies of the type reported here, the provider prescribing pattern variables appear to offer promise as identifying variables. For example, future work could use instrumental variables or parametric selection models to control for unobserved factors associated with both treatment selection and outcomes when examining the effects of asthma treatments on health care utilization. This general approach is likely to have broad applicability to other medical conditions and treatments as well. 


\section{$\underline{\text { REFERENCES }}$}

Alan, Sule, Thomas F. Crossley, Paul Grootendorst and Michael R. Veall [2002], "The Effects of Drug Subsidies on Out-of-Pocket Prescription Drug Expenditures by Seniors: Regional Evidence from Canada", Journal of Health Economics, 21:5, September, pp. 805-826.

Beddhu, Srinivasan, Frank J. Bruns, Melissa Saul, Patricia Seddon, and Mark L. Zeidel [2000],

"A Simple Comorbidity Scale Predicts Clinical Outcomes and Costs in Dialysis

Patients," American Journal of Medicine, 108(8): 609-613.

Berndt, Ernst R. [2002], "Pharmaceuticals in U.S. Health Care: Determinants of Quantity and Price", Journal of Economic Perspectives, 16(4):

Berndt, Ernst R. [2001], "The U.S. Pharmaceutical Industry: Why Major Growth in Times of Cost Containment?", Health Affairs, 20:2, March/April, pp. 100-14.

Blomqvist, Ake [2001], "Does the Economics of Moral Hazard Need to be Revisited? A Comment on the Paper by John Nyman", Journal of Health Economics, 20:2, March, pp. 283-88.

Bourguignon, Francois, Martin Fournier and Marc Gurgand [2001], "Selection Bias Correction Based on the Multinomial Logit Model," Paris: Center for Research on Econometrics and Statistics, unpublished working paper, December 27. Available at http://www.crest.fr/pageperso/lmi/gurgandselmlog.htm.

D'Hoore W, Bouckaert A, Tilquin C. Practical Considerations on the Use of the Charlson Comorbidity Index with Administrative Data Bases. J Clin Epidemol 1996;49(12):14291433.

Donahue J.G., Weiss S.T., Livingston J.M., Goetsch M.A., Greineder D.K., Platt R. [1997], Inhaled Steroids and the Risk of Hospitalization for Asthma. Journal of the American Medical Association. 277(11): 877-891.

Feenberg, Daniel and Jonathan Skinner [1994], "The Risk and Duration of Catastrophic Health Care Expenditures", Review of Economics and Statistics, 76, pp. 333-47.

Frischer M., Heathe H., Chapman S., Norwood J., Bashford J., and Millson D. [1999], Should the Corticosteroid to Bronchodilator Ratio be Promoted as a Quality Prescribing Marker? Public Health 113(5): 247-250.

Gottlieb D.J., Belser A.S., O’Connor G.T. [1995], Poverty, Race, and Medication Use are Correlates of Asthma Hospitalization Rates. Chest. 108: 28-35.

Grootendorst, Paul [2002], "Beneficiary Cost Sharing under Canadian Provincial Prescription Drug Benefit Programs: History and Assessment", Canadian Journal of Clinical Pharmacology, in press. 
Harris, B. L., A. Stergachis, and L. D. Ried [1990], "The Effect of Drug Co-payments on Utilization and Cost of Pharmaceuticals in a Health Maintenance Organization", Medical Care, 28, pp. 907-17.

IMS Health [2002], "IMS Reports 16.9\% Growth in 2001 U.S. Prescription Sales". Available at $<$ http://www.imshealth.com/public/structure $>$.

Jain P. and Golish J.A. [1996], Clinical Management of Asthma in the 1990s: Current Therapy and New Directions. Drugs 52 Suppl. 6: 1-11.

Johnson, R. E., M. J. Goodman, M.C. Hornbrook, and M. B. Eldredge [1997], "The Effect of Increased Prescription Drug Cost Sharing on Medical Care Utilization and Expenses of Elderly Health Maintenance Organization Members", Medical Care, 35, pp. 1119-31.

Laumann J.M. and Bjornson D.C. [1998], Treatment of Medicaid Patients with Asthma: Comparison with Treatment Guidelines Using Disease-Based Drug Utilization Review Methodology. Annals of Pharmacotherapy. 32(12): 1290-1294.

Lee, L. F. [1983], “Generalized Econometric Models with Selectivity,” Econometrica, 51:507512.

Leibowitz, Arleen, Willard G. Manning, Emmett B. Keeler, Naihua Duan, Kathleen N. Lohr and Joseph P. Newhouse [1985], "The Effect of Cost Sharing on the Use of Medical Services by Children", Santa Monica, CA: The RAND Publication Series, R-3287-HHS, September, $33 \mathrm{pp}$.

Leibowitz, Arleen, Willard G. Manning and Joseph P. Newhouse [1985], "The Demand for Prescription Drugs as a Function of Cost Sharing," Social Science and Medicine, 21:10, pp. 1063-70.

Levine, Sharon, David Campen, Mirta Millares and Anthony Barrueta [2000], "Kaiser Permanente's Prescription Drug Benefit," Health Affairs, 19(2): 17-22.

Majeed A., Ferguson J., and Field J. [1999], "Prescribing of Beta-2 Agonists and Inhaled Steroids in England: Trends Between 1992 and 1998, and Association with Material Deprivation, Chronic Illness and Asthma Mortality Rates.” Journal of Public Health Medicine. 21(4): 395-400.

Manning, Willard G. and M. Susan Marquis [2001], "Health Insurance: Tradeoffs Revisited", Journal of Health Economics, 20:2, March, pp. 289-93.

Manning, Willard G. and M. Susan Marquis [1996], "Health Insurance: The Tradeoff Between Risk Pooling and Moral Hazard", Journal of Health Economics, 15, pp. 609-40.

Manning, Willard G. et al. [1986], "How Cost Sharing Affects the Use of Ambulatory Mental 
Health Services," Journal of the American Medical Association, 256:1930-34.

Marquis, M. Susan [1985], "Cost-Sharing and Provider Choice", Journal of Health Economics, 4:137-57.

National Asthma Education Program (NAEP) [1991], Expert Panel Report: Guidelines for the Diagnosis and Management of Asthma. National Heart, Lung, and Blood Institute.

Nestor A., Calhoun A.C., Dickson M., and Kalik C.A. [1998], "Cross-Sectional Analysis of the Relationship Between National Guideline Recommended Asthma Drug Therapy and Emergency/Hospital Use Within a Managed Care Population.” Annals of Allergy Asthma Immunology. 81(4): 327-330.

Newhouse, Joseph P. and the Insurance Experiment Group [1993], Free for All? Lessons from the RAND Health Insurance Experiment, Cambridge, MA: Harvard University Press.

Nyman, John [1999], "The Economics of Moral Hazard Revisited", Journal of Health Economics, 18 , pp. 811- 824.

Pharmacy Benefit Management Institute [2001], Takeeda-Lilly Prescription Drug Benefit Cost and Plan Design Survey Report, Temple AZ.

Poirier, S., Jacques LeLorier, V. Page and A. Lacour [1998], "The Effect of a \$2 Co-Payment on Prescription Refill Rates of Quebec Elderly and Its Relationship to Socioeconomic Status", Canadian Pharmaceutical Journal, 131, pp. 30-34.

Shelley M., Croft P., Chapman S., and Pantin C. [2000], "Is the Quality of Asthma Prescribing, as Measured by the General Practice Ratio of Corticosteroid to Bronchodilator, Associated with Asthma Morbidity?" Journal of Clinical Epidemiology. 53(12): 12171221.

Sin D, J.V. Tu . [2001], "Underuse of Inhaled Steroid Therapy in Elderly Patients with Asthma," Chest, 119: 720-725.

Smith, D. G. [1993], "The Effects of Co-Payments and Generic Substitution on the Use and Costs of Prescription Drugs", Inquiry, 30, pp. 189-98.

Stafford, Randall S., Jun Ma, Stan N. Finkelstein, Kenan Haver and Iain M. Cockburn [2002], "National Trends in Asthma Visits and Asthma Pharmacotherapy, 1978-2002", Palo Alto CA: Stanford Center for Research in Disease Prevention, unpublished manuscript, September, $22 \mathrm{pp}$.

Suissa S., Ernst P., Bolvin J.F., et al. [1994], "A Cohort Analysis of Excess Mortality in Asthma and the Use of Inhaled Beta-Agonists." American Journal of Respiratory Critical Care Medicine. 149(3 pt 1): 604-610. 
Tamblyn, R., R. Laprise, J. A. Hanley, M. Abrahamowitz, S. Scott, N. May, J. Hurley, R. Grad, E. Latimer, R. Perreault, P. McLeod, A. Huang, P. Larochelle, and L. Mallet [2001], "Adverse Events Associated with Prescription Drug Cost-Sharing Among Poor and Elderly Persons", Journal of the American Medical Association, 285, pp. 421-429.

Witt, Whitney P., William H. Crown, Jon Maguire, Ernst R. Berndt and Stan N. Finkelstein [2002], "Asthma in the Family: Determining Family-Level Medical Services Use and Healthcare Expenditures", Cambridge, MA: Medstat., unpublished manuscript, September, $47 \mathrm{pp}$.

Zeckhauser, Richard J. [1970], "Medical Insurance: A Case Study of the Tradeoff Between Risk Spreading and Appropriate Incentives", Journal of Economic Theory, 2, pp. 10-26. 


\section{FOOTNOTES}

${ }^{1}$ See Zeckhauser [1970] for a seminal discussion. For more recent analyses, see the exchanges among Nyman [1999], Blomqvist [2001], and Manning and Marquis [1996,2001].

${ }^{2}$ For evidence from the RAND Health Insurance Experiment, see Newhouse [1993], Manning et al. [1986], Leibowitz, Manning and Newhouse [1985], and Marquis [1985]. More recent evidence for a more aged population is given in Feenberg and Skinnner [1994].

${ }^{3}$ The term copayment typically refers to fixed payments by the individual for service received (e.g., five dollars for each generic prescription); coinsurance typically refers to a fixed percentage payment by the individual (e.g., $20 \%$ of the retail price of the drug). In this paper, we use the term copayment to refer to any out of pocket payments by consumers for drugs or other services.

${ }^{4}$ Berndt [2002]; also see Berndt [2001].

${ }^{5}$ IMS Health [2002].

${ }^{6}$ For policies and impacts of changing prescription drug cost-sharing provisions in Canada, see Alan et al. [2002], Grootendorst [2002], Poirier et al. [1998] and Tamblyn et al. [2001].

${ }^{7}$ For further discussion, see Berndt [2002] and the references cited therein.

${ }^{8}$ See Pharmacy Benefit Management Institute [2001].

${ }^{9}$ For related empirical evidence (much of it quite dated), see Harris et al. [1990], Johnson et al. [1997], Leibowitz, Manning and Newhouse [1985], Marquis [1985] and Smith [1993].

${ }^{10}$ For related empirical analyses, see Keeler et al. [1985], Leibowitz et al. [1985], and Newhouse [1993].

${ }^{11}$ See, for example, Levine, Campen, Millares and Barrueta [2000].

${ }^{12}$ Gottlieb, Belser, and O’Connor [1995]; Frischer, et al. [1999]; Shelley, et al. [2000].

${ }^{13}$ See Jain and Golish [1996]; Majeed, Ferguson, and Field [1999]; Nestor, et al. [1998]; and Suissa, et al. [1994].

${ }^{14}$ Majeed, Ferguson, and Field [1999]; Nestor, et al. [1998]; Suissa, et al. [1994]; Laumann and Bjornson [1998]; and Donahue et al. [1997].

${ }^{15}$ Frischer, et al. [1999]; Shelley, et al. [2000].

${ }^{16}$ See, for example, Gottlieb, Belser and O’Connor [1995].

${ }^{17}$ For further details, see D’Hoore, Bouckaert, and Tilquin. [1996].

${ }^{18}$ See, for example, D’Hoore, Bouckaert, and Tilquin. [1996], and Beddhu et al. [2000]. 
Table 1: Summary of Asthma Patient Characteristics by Insurance Plan Type, 1995-2000

\begin{tabular}{l}
\hline $\mathbf{N}$ \\
Trigger Type \\
(1) 2 OP Asthma Claims \\
(2) Asthma ER + Asthma RX \\
(3) IP Resp. Inf. + Asthma \\
(4) IP Asthma \\
(5) 2 Asthma RX
\end{tabular}

Mean Age
$\%$ Females

\section{Geographic region}

Northeast

North central

South

West

Year of Trigger
1996
1997
1998
1999

Member Type

Employee

Spouse

Dependents

4-11 years

$12-18$ years

Other

\section{County Race/Ethnicity}

White

$$
\begin{aligned}
& 0-25 \% \\
& 26-50 \% \\
& 51-75 \% \\
& 76-100 \%
\end{aligned}
$$

\section{Black}

0 - 25\%

$26-50 \%$

$51-75 \%$

$76-100 \%$

Hispanic

0 - $25 \%$

$26-50 \%$

$51-75 \%$

$76-100 \%$

FFS

44,926

$37.05 \%$
$0.69 \%$
$0.04 \%$
$0.26 \%$
$61.97 \%$

$36.91 \%$

$0.82 \%$

$0.08 \%$

$0.32 \%$

$61.87 \%$

34.09

$57.41 \%$

\subsection{9}

$52.09 \%$

$15.63 \%$

$67.01 \%$

$12.05 \%$

$5.31 \%$

$34.67 \%$

$20.21 \%$

$21.99 \%$

$23.13 \%$

$40.76 \%$

$22.02 \%$

$37.21 \%$

$15.76 \%$

$15.94 \%$

$5.51 \%$

$13.13 \%$
$13.55 \%$
$14.62 \%$
$58.71 \%$

$28.43 \%$

$18.28 \%$

$19.86 \%$

$33.43 \%$

$<.01$

$<.01$

$<.01$

$38.68 \%$
$17.55 \%$
$43.77 \%$
$27.97 \%$
$14.24 \%$
$1.57 \%$

$40.16 \%$

$20.73 \%$

$39.11 \%$

$19.30 \%$

$15.45 \%$

$4.37 \%$

$<.01$

$<.01$

$<.01$

$<.01$

$<.01$

$<.01$

$\begin{array}{cccc}0.49 \% & 0.84 \% & 0.59 \% & <.01 \\ 1.44 \% & 7.00 \% & 3.05 \% & <.01 \\ 21.25 \% & 35.73 \% & 25.44 \% & <.01 \\ 76.82 \% & 56.43 \% & 70.92 \% & <.01 \\ & & & <.01 \\ 91.70 \% & 76.30 \% & 87.24 \% & <.01 \\ 8.02 \% & 22.85 \% & 12.31 \% & <.01 \\ 0.26 \% & 0.85 \% & 0.43 \% & <.01 \\ 0.01 \% & 0.00 \% & 0.01 \% & 0.15 \\ & & & \\ 96.76 \% & 93.35 \% & 95.77 \% & <.01 \\ 2.67 \% & 5.52 \% & 3.49 \% & <.01 \\ 0.52 \% & 1.13 \% & 0.69 \% & <.01 \\ 0.06 \% & 0.01 \% & 0.04 \% & <.01\end{array}$


Table 1: Summary of Asthma Patient Characteristics by Insurance Plan Type, 1995-2000

\begin{tabular}{lcccc}
\hline & FFS & Non-FFS & Total & P-Value \\
\hline Other & & & & $<.01$ \\
$\quad 0-25 \%$ & $99.94 \%$ & $99.83 \%$ & $99.91 \%$ & $<.01$ \\
$26-50 \%$ & $0.02 \%$ & $0.15 \%$ & $0.06 \%$ & $<.01$ \\
$51-75 \%$ & $0.04 \%$ & $0.02 \%$ & $0.03 \%$ & 0.21 \\
$76-100 \%$ & $0.01 \%$ & $0.00 \%$ & $0.01 \%$ & 0.20 \\
County Mean Household Income & $\mathbf{2 7 , 0 0 1}$ & $\mathbf{3 1 , 2 2 3}$ & $\mathbf{2 8 , 2 6 9}$ & $<.01$ \\
\hline
\end{tabular}


Table 2: Co-Morbidities among Asthma Patients

by Insurance Plan Type, 1995-2000

\begin{tabular}{|c|c|c|c|c|}
\hline & FFS & Non-FFS & Total & P-Value \\
\hline All Patients, $\mathbf{N}$ & 44,926 & 18,305 & 63,231 & $\mathrm{n} / \mathrm{a}$ \\
\hline \# Major diagnostic categories & 6.26 & 5.35 & 6.00 & $<.01$ \\
\hline Charlson Comorbidity Index & 0.79 & 0.62 & 0.74 & $<.01$ \\
\hline \multicolumn{5}{|l|}{ Asthma-specific Comorbidites: } \\
\hline Allergic Rhinitis & $23.27 \%$ & $18.67 \%$ & $21.94 \%$ & $<.01$ \\
\hline Anxiety & $2.39 \%$ & $2.35 \%$ & $2.38 \%$ & 0.78 \\
\hline Depression & $10.31 \%$ & $8.17 \%$ & $9.69 \%$ & $<.01$ \\
\hline GI Disorders & $24.55 \%$ & $20.73 \%$ & $23.45 \%$ & $<.01$ \\
\hline Migraine & $6.02 \%$ & $5.05 \%$ & $5.74 \%$ & $<.01$ \\
\hline Patients Aged 4-11, $\mathrm{N}$ & 7,084 & 5,123 & 12,207 & $\mathrm{n} / \mathrm{a}$ \\
\hline \# Major diagnostic categories & 5.19 & 4.85 & 5.05 & $<.01$ \\
\hline Charlson Comorbidity Index & 0.55 & 0.51 & 0.53 & $<.01$ \\
\hline \multicolumn{5}{|l|}{ Asthma-specific Comorbidites: } \\
\hline Allergic Rhinitis & $25.72 \%$ & $20.69 \%$ & $23.61 \%$ & $<.01$ \\
\hline Anxiety & $0.78 \%$ & $0.49 \%$ & $0.66 \%$ & 0.05 \\
\hline Depression & $4.29 \%$ & $2.81 \%$ & $3.67 \%$ & $<.01$ \\
\hline GI Disorders & $15.30 \%$ & $14.50 \%$ & $14.97 \%$ & 0.22 \\
\hline Migraine & $3.08 \%$ & $3.10 \%$ & $3.09 \%$ & 0.93 \\
\hline Patients Aged 12-64, N & 37,842 & 13,182 & 51,024 & $\mathrm{n} / \mathrm{a}$ \\
\hline \# Major diagnostic categories & 6.46 & 5.55 & 6.22 & $<.01$ \\
\hline Charlson Comorbidity Index & 0.84 & 0.66 & 0.79 & $<.01$ \\
\hline \multicolumn{5}{|l|}{ Asthma-specific Comorbidites: } \\
\hline Allergic Rhinitis & $22.81 \%$ & $17.88 \%$ & $21.53 \%$ & $<.01$ \\
\hline Anxiety & $2.69 \%$ & $3.07 \%$ & $2.79 \%$ & 0.02 \\
\hline Depression & $11.44 \%$ & $10.26 \%$ & $11.13 \%$ & $<.01$ \\
\hline GI Disorders & $26.28 \%$ & $23.15 \%$ & $25.47 \%$ & $<.01$ \\
\hline Migraine & $6.57 \%$ & $5.81 \%$ & $6.38 \%$ & $<.01$ \\
\hline
\end{tabular}


Table 3: Plan-Level Average Copayments

by Insurance Plan Type, 1995-2000

\begin{tabular}{|c|c|c|c|c|}
\hline & FFS & Non-FFS & Total & P-Value \\
\hline $\mathbf{N}^{*}$ & 33,828 & 18,214 & 52,042 & $\mathrm{n} / \mathrm{a}$ \\
\hline Prescription Copayment & 5.20 & 8.64 & 6.20 & $<.01$ \\
\hline For Asthma Related Drugs & 5.06 & 8.04 & 5.92 & $<.01$ \\
\hline For Non-Asthma Related Drugs & 5.24 & 8.83 & 6.28 & $<.01$ \\
\hline Outpatient Visit Copayment & 7.71 & 8.10 & 7.84 & $<.01$ \\
\hline For Asthma Related Visits & 7.83 & 8.25 & 7.97 & $<.01$ \\
\hline For Non-Asthma Related Visits & 7.69 & 8.09 & 7.83 & $<.01$ \\
\hline Emergency Room Visit Copayment & 10.24 & 13.03 & 11.22 & $<.01$ \\
\hline For Asthma Related Visits & 15.25 & 13.92 & 14.79 & $<.01$ \\
\hline For Non-Asthma Related Visits & 9.89 & 12.94 & 10.96 & $<.01$ \\
\hline Inpatient Visit Copayment & 16.12 & 2.78 & 11.45 & $<.01$ \\
\hline For Asthma Related Visits & 18.07 & 1.79 & 12.37 & $<.01$ \\
\hline For Non-Asthma Related Visits & 15.92 & 2.94 & 11.38 & $<.01$ \\
\hline
\end{tabular}

* Average copayment was not available for all plans. 
Table 4: Annualized Asthma Medication Claims

by Insurance Plan Type, 1995-2000

\begin{tabular}{|c|c|c|c|c|}
\hline & FFS & Non-FFS & Total & P-Value \\
\hline $\mathbf{N}$ & 44,926 & 18,305 & 63,231 & $\mathrm{n} / \mathrm{a}$ \\
\hline Ratio of Controller to Reliever & 1.49 & 1.17 & 1.40 & $<.01$ \\
\hline Number of Asthma Prescriptions & 4.89 & 4.17 & 4.68 & $<.01$ \\
\hline Bronchodilators & 0.71 & 0.37 & 0.61 & $<.01$ \\
\hline Oral Steroids & 0.45 & 0.45 & 0.45 & 0.69 \\
\hline SABAs & 2.14 & 2.11 & 2.13 & 0.20 \\
\hline Inhaled Steroids & 1.22 & 0.90 & 1.13 & $<.01$ \\
\hline Luekotriene Modifiers & 0.24 & 0.28 & 0.25 & $<.01$ \\
\hline Anticholinergics & 0.12 & 0.05 & 0.10 & $<.01$ \\
\hline \multicolumn{5}{|l|}{ Estimated Days of Therapy } \\
\hline Bronchodilators & 21.99 & 10.43 & 18.64 & $<.01$ \\
\hline Oral Steroids & 5.91 & 4.59 & 5.53 & $<.01$ \\
\hline SABAs & 46.44 & 41.75 & 45.09 & $<.01$ \\
\hline Inhaled Steroids & 30.19 & 20.96 & 27.51 & $<.01$ \\
\hline Luekotriene Modifiers & 8.89 & 9.09 & 8.94 & 0.61 \\
\hline Anticholinergics & 2.89 & 1.07 & 2.36 & $<.01$ \\
\hline \multicolumn{5}{|l|}{ Units Dispensed } \\
\hline Bronchodilators & 34.05 & 14.86 & 28.50 & $<.01$ \\
\hline Oral Steroids & 18.65 & 18.16 & 18.51 & 0.44 \\
\hline SABAs & 78.01 & 79.50 & 78.44 & 0.37 \\
\hline Inhaled Steroids & 31.33 & 21.46 & 28.47 & $<.01$ \\
\hline Luekotriene Modifiers & 12.73 & 12.44 & 12.65 & 0.63 \\
\hline Anticholinergics & 5.26 & 2.36 & 4.42 & $<.01$ \\
\hline \multicolumn{5}{|l|}{ Selection of Asthma Medication } \\
\hline Bronchodilators & $15.94 \%$ & $9.66 \%$ & $14.12 \%$ & $<.01$ \\
\hline Oral Steroids & $23.71 \%$ & $26.42 \%$ & $24.50 \%$ & $<.01$ \\
\hline SABAs & $76.57 \%$ & $80.63 \%$ & $77.75 \%$ & $<.01$ \\
\hline Inhaled Steroids & $35.00 \%$ & $31.95 \%$ & $34.11 \%$ & $<.01$ \\
\hline Luekotriene Modifiers & $5.88 \%$ & $6.62 \%$ & $6.09 \%$ & $<.01$ \\
\hline Anticholinergics & $4.14 \%$ & $2.13 \%$ & $3.56 \%$ & $<.01$ \\
\hline
\end{tabular}


Table 5: Annualized Per Beneficiary Asthma-Related Health Care Utilization by Insurance Plan Type, 1995-2000

\begin{tabular}{lcccc} 
& FFS & Non-FFS & Total & P-Value \\
\hline $\mathbf{N}$ & $\mathbf{4 4 , 9 2 6}$ & $\mathbf{1 8 , 3 0 5}$ & $\mathbf{6 3 , 2 3 1}$ & n/a \\
\hline Measures of Health Care Use & & & & \\
$\quad$ Emergency room visits & 0.38 & 0.37 & 0.38 & 0.09 \\
Hospitalizations & 0.08 & 0.05 & 0.07 & $<.01$ \\
Hospital Days & 0.36 & 0.23 & 0.32 & $<.01$ \\
Outpatient visits & 5.46 & 1.40 & 4.29 & $<.01$ \\
& & & & \\
\hline
\end{tabular}


Table 6

Multinomial Logit Model of Medication Selection: Patients in FFS Plans Controller Alone

Paramater Estimate

Controller + Reliever

\begin{tabular}{|c|c|c|c|c|}
\hline & raramater cstimate & 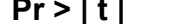 & raramater cstimate & $r \mid>0$ \\
\hline Intercept & -3.4707 & $=<0.001$ & $\begin{array}{ll}-2.2667 \\
\end{array}$ & $<<0.001$ \\
\hline \multicolumn{5}{|l|}{ Demographics } \\
\hline Region North Central & -0.3932 & $<0.001$ & -0.1591 & 0.0020 \\
\hline Region Northeast & -0.0290 & 0.8430 & -0.0014 & 0.9900 \\
\hline Region West & -0.1649 & 0.1410 & -0.0199 & 0.8070 \\
\hline Female & -0.0119 & 0.7700 & -0.1062 & $<0.001$ \\
\hline Adult & 0.8893 & $<0.001$ & 0.2170 & $<0.001$ \\
\hline \multicolumn{5}{|l|}{ Clinical Characteristics } \\
\hline Allergic Rhinitis & 0.5128 & $<0.001$ & 0.6086 & $<0.001$ \\
\hline Migraine & -0.0270 & 0.7380 & -0.0390 & 0.5220 \\
\hline Depression & -0.1795 & 0.0060 & -0.0067 & 0.8850 \\
\hline GI disorders & -0.0537 & 0.2740 & -0.1022 & 0.0050 \\
\hline Sinusitis & -0.0655 & 0.1520 & 0.0110 & 0.7400 \\
\hline Anxiety disorders & -0.1843 & 0.1320 & -0.2209 & 0.0150 \\
\hline \#3-digit ICD-9 codes & 0.0483 & $<0.001$ & 0.0481 & $<0.001$ \\
\hline \multicolumn{5}{|l|}{ County Characteristics } \\
\hline County Average Income $\$ 15-20 \mathrm{~K}$ & 0.2960 & 0.3290 & -0.0804 & 0.6810 \\
\hline County Average Income $\$ 20-25 \mathrm{~K}$ & 0.4274 & 0.1550 & 0.0241 & 0.9010 \\
\hline County Average Income $\$ 25-35 \mathrm{~K}$ & 0.3661 & 0.2240 & 0.0713 & 0.7140 \\
\hline County Average Income $>\$ 35 \mathrm{~K}$ & 0.8503 & 0.0050 & 0.1602 & 0.4170 \\
\hline \multicolumn{5}{|l|}{ Copay Variables } \\
\hline Ratio of Controller/Reliever Copayment & -0.0667 & 0.5030 & 0.0308 & 0.6820 \\
\hline Tax Provider ID Controller \% & 6.4705 & $<0.001$ & 1.1769 & 0.1840 \\
\hline Tax Provider ID Combination $\%$ & 1.0605 & 0.0320 & 4.1513 & $<0.001$ \\
\hline Chi2(3)* & 60.3200 & $<<0.001$ & 164.5700 & $<<0.001$ \\
\hline LR chi2(38) & 1816.3600 & $<0.001$ & & \\
\hline Psuedo-R2 & 0.0341 & & & \\
\hline Number of Observations & 26379 & & & \\
\hline
\end{tabular}

Notes: Referance category is Reliever Alone. * Chi-square test for significance of copay variables. 
Table 7

Multinomial Logit Model of Medication Selection: Patients in Non-FFS Plans

Intercept

Demographics

Region North Central

Region Northeast

Region West

Female

Adult

Clinical Characteristics

Allergic Rhinitis

Migraine

Depression

GI disorders

Sinusitis

Anxiety disorders

\#3-digit ICD-9 codes

County Characteristics

County Average Income \$15-20K

County Average Income $\$ 20-25 \mathrm{~K}$

County Average Income $\$ 25-35 \mathrm{~K}$

County Average Income $>\$ 35 \mathrm{~K}$

\section{Copay Variables}

Ratio of Controller/Reliever Copayments

Tax ID Prescriber Controller \%

Tax ID Prescriber Combination\%

Chi2(3) ${ }^{*}$

LR chi2(38)

Psuedo-R2

Number of Observations

\section{Controller Alone}

Paramater Estimate

$-6.1203$

$\operatorname{Pr}>|\mathbf{t}|$

$$
<0.001
$$

$-0.2239$

$-0.2124$

$-0.2940$

$-0.0941$

1.1020

0.8721

$-0.0033$

0.0975

$-0.0568$

0.0685

$-0.6812$

0.0667

$-0.2739$

$-0.1448$

$-0.1357$

$-0.3545$

$$
\begin{aligned}
& 0.0880 \\
& 0.0960 \\
& 0.0170 \\
& 0.2870
\end{aligned}
$$

$<0.001$

$<0.001$

0.9870

0.5540

0.6290

0.5400

0.0450

$<0.001$

0.5990

0.7660

0.7770

0.4770

0.0816

11.4306

6.6881

16.1400

598.6700

0.0463

6768

0.0030

0.0650

0.0011

$<0.001$

Controller + Reliever

Paramater Estimate

$-5.2240$

$-0.1658$

$-0.0735$

$-0.3179$

$-0.1897$

0.2973

0.7965

0.1745

$-0.1856$

$-0.1773$

0.0651

$-0.3315$

0.0632

$-0.2224$

$-0.1310$

$-0.2558$

$-0.3857$

0.6444

1.0697

11.1009

53.6800
$\operatorname{Pr}>|\mathbf{t}|$

$<0.001$

0.0440

0.3350

$<0.001$

$<0.001$

$<0.001$

$<0.001$

0.2130

0.1160

0.0230

0.3690

0.1250

$<0.001$

0.5050

0.6770

0.4080

0.2280
$<0.001$

0.6640

$<0.001$

$<0.001$

Note: Referamce category is Reliever Alone 
Table 8. Log-Linear Regression Results: Patients in FFS Plans [Dependent Variable: Log(Total Payments)]

\section{Controller Alone}

Selectivity Adjusted NOT Adjusted

Parameter $\operatorname{Pr}>|\mathbf{t}|$ Parameter $\operatorname{Pr}>|\mathbf{t}|$

Estimate

1.96660 .1070

Estimate

Intercept

Demographics

Region North Central

Region Northeast

Region West

Female

Adult

Clinical Characteristics

Allergic Rhinitis

Migraine

Depression

GI disorders

Sinusitis

Anxiety disorders

\#3-digit ICD-9 codes

County Characteristics

County Average Income \$15-

County Average Income \$20-

County Average Income \$25-

County Average Income

\section{Correlations}

Lamda(1)

Lamda(2)

Lamda(3)

R-square

Hausman Test Statistic

Number of Observations

$0.2803<0.001$

$0.1217 \quad 0.3370$

$0.0961 \quad 0.2430$

$-0.0138 \quad 0.6880$

$0.0208 \quad 0.8410$

$-0.1254 \quad 0.0030$

$\begin{array}{ll}-0.0165 & 0.7140\end{array}$

$0.3995<0.001$

$0.0789 \quad 0.0090$

$0.0539 \quad 0.0510$

$0.0877<0.001$

$\begin{array}{ll}-0.1565 & 0.6690\end{array}$

$\begin{array}{ll}-0.2616 & 0.4660\end{array}$

$-0.1384 \quad 0.6950$

$-0.42950 .2400$

$-10.5181<0.001$

$-7.8338<0.001$

$-0.0510$

0.4597
$-13.9200<0.001$
3903

Controller + Reliever

Selectivity Adjusted NOT Adjusted

Parameter $\operatorname{Pr}>|\mathbf{t}| \quad$ Parameter $\operatorname{Pr}>\mid \mathbf{t}$

Estimate

$5.1129<0.001 \quad 6.1208<0.001$

$0.1709 \quad 0.1370$

$-3.1896<0.001$

$\begin{array}{cc}0.0633 & 0.1480 \\ 0.0510 & 0.6300 \\ -0.0021 & 0.9790 \\ -0.0282 & 0.3620 \\ 0.6823 & <0.001 \\ & \\ 0.1099 & 0.0010 \\ -0.0320 & 0.5810 \\ 0.3139 & <0.001 \\ 0.0648 & 0.0710 \\ 0.0222 & 0.5120 \\ 0.0651 & 0.4730 \\ 0.1055 & <0.001\end{array}$

0.2251

$0.2251<0.001$

$0.0421 \quad 0.5890$

$0.0357 \quad 0.6270$

$0.0364 \quad 0.1000$

0.2500

0.0010

$-0.1567<0.001$

$0.0102 \quad 0.8330$

$0.3262<0.001$

$0.1248<0.001$

$-0.0033 \quad 0.8630$

$0.2036 \quad 0.0100$

$0.0763<0.001$

$\begin{array}{ll}-0.0311 & 0.8940\end{array}$

0.0583

0.6350

$-0.0493 \quad 0.8310$

$0.0375 \quad 0.8710$

0.8270

$-0.0055$

0.7390

0.9670

0.1420

$-7.0098<0.001$

$-4.1839<0.001$

$-5.4709<0.001$ $\begin{array}{ll}0.0277 & 0.2860 \\ -0.0277 & 0.6590\end{array}$

$-0.0277 \quad 0.6590$

$-0.0488 \quad 0.2720$

$0.0018 \quad 0.9160$

$0.6550<0.001$

$0.1311<0.001$

$-0.0150 \quad 0.6480$

$0.2709<0.001$

$0.0992<0.001$

$-0.0139 \quad 0.4530$

$0.0827 \quad 0.1090$

$0.0986<0.001$

$0.0944 \quad 0.3860$

$0.0696 \quad 0.5190$

$0.0906 \quad 0.4010$

$0.0553 \quad 0.6140$

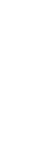

Reliever Alone

Selectivity Adjusted NOT Adjusted

Parameter $\operatorname{Pr}>|\mathbf{t}|$ Parameter $\operatorname{Pr}>|\mathbf{t}|$

Estimate

Estimate

$2.1427<0.001 \quad 5.0938<0.001$

$\begin{array}{cc}0.2460 & <0.001 \\ -0.0985 & 0.3030\end{array}$

$-0.0547 \quad 0.1360$

$-0.1831 \quad 0.0160$

$\begin{array}{rrrr}-0.0528 & 0.5290 & -0.1999 & <0.001 \\ 0.0295 & 0.4590 & 0.0208 & 0.2720\end{array}$

$\begin{array}{llll}0.1375 & 0.0510 & 0.6722<0.001\end{array}$

$-0.0451 \quad 0.0180$

$-0.0002 \quad 0.9950$

$0.4994<0.001$

$0.0661 \quad 0.1720$

$0.0220 \quad 0.3810$

$0.3699<0.001$

$0.1119<0.001$

$0.1312<0.001$

$-0.0284 \quad 0.5050$

$0.4013<0.001$

$0.0460 \quad 0.0640$

$\begin{array}{ll}-0.0107 & 0.6360\end{array}$

$0.2874<0.001$

$0.1324<0.001$

$\begin{array}{ll}0.0111 & 0.9420\end{array}$

$0.1220 \quad 0.3730$

$0.1146 \quad 0.4000$

$0.1104 \quad 0.4190$

$0.0816 \quad 0.5560$

$-0.03790 .8140$

$-0.3223 \quad 0.0290$

$-8.9698<0.001$

$-8.2394<0.001$

$-3.1968<0.001$

0.4791

$-189.900<0.001<0.001$

$62.0700<0.001$

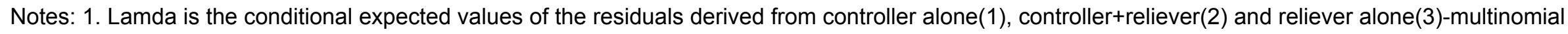
logit equation. 2. P-values are derived from bootstrapped standard errors. 
Table 9. Log-Linear Regression Results: Patients in Non-FFS Plans [Dependent Variable: Log(Total Payments)]

Controller Alone

Selectivity Adjusted NOT Adjusted

Parameter $\operatorname{Pr}>|\mathbf{t}|$ Parameter $\operatorname{Pr}>\mid \mathbf{t}$

Intercept

Demographics

Region North Central

Region Northeast

Region West

Female

Adult

Clinical Characteristics

Allergic Rhinitis

Migraine

Depression

GI disorders

Sinusitis

Anxiety disorders

\#3-digit ICD-9 codes

County Characteristics

County Average Income \$15$20 \mathrm{~K}$

County Average Income \$20-

25K

County Average Income \$25-

$35 \mathrm{~K}$

County Average Income $>\$ 35 \mathrm{~K}$

\section{Correlations}

Lamda(1)

Lamda(2)

Lamda(3)

R-square

Hausman Test Statistic

Number of Observations

\section{Estimate}

3.1781

Estimate

$-0.0192$

0.0627

$-0.3234$

$-0.0143$

0.0170

0.2900

0.1048

0.4014

0.0911

$-0.0216$

0.1594

$0.1413<0.001$

5.6622

$0.1277<0.001$

$-0.1889 \quad 0.6200$

$-0.4244 \quad 0.2990$

$-0.5821 \quad 0.2100$

$-0.4976 \quad 0.2950$

$\begin{array}{ll}-5.6860 & 0.0000 \\ -7.3977 & 0.0000\end{array}$

0.4563

16.2200
Controller+Reliever

Selectivity Adjusted NOT Adjusted

Parameter $\operatorname{Pr}>|\mathbf{t}| \quad$ Parameter $\operatorname{Pr}>\mid \mathbf{t}$

\section{Estimate}

Estimate

$4.0577<0.001$

$\begin{array}{ll}-0.0674 & 0.5690\end{array}$

$-0.0121 \quad 0.9220$

0.0679

0.4200

$-0.1499 \quad 0.0650$

$0.0515 \quad 0.3350$

$0.0329 \quad 0.6670$

$0.4876<0.001$

$0.5631<0.001$

$0.2727 \quad 0.0210$

$0.0991 \quad 0.4890$

$0.1509 \quad 0.0840$

$-0.0253 \quad 0.8820$

$0.5120<0.001$

$0.2330<0.001$

$0.1223 \quad 0.0060$

$\begin{array}{rr}0.0048 & 0.9590\end{array}$

$0.0599 \quad 0.8400$

$0.0600 \quad 0.1570$

$0.1935 \quad 0.1880$

$0.1249<0.001$

$-0.2485 \quad 0.5700$

$0.2593 \quad 0.4400$

$-0.4548 \quad 0.2640$

$0.1860 \quad 0.5540$

$-0.5504 \quad 0.1730$

0.121

0.7070

0.0628

$-0.5362 \quad 0.2040$

$0.2382 \quad 0.4620$

0.1771

$-3.4653 \quad 0.0010$

$-2.1676<0.001$

$-5.0881<0.001$

0.4381
$3.5437<0.001$

$0.0688 \quad 0.2240$

$0.1263 \quad 0.1500$

$-0.1729$

$0.0520 \quad 0.3010$

$0.6438<0.001$

$0.3353<0.001$

$0.1046 \quad 0.1190$

$0.2548 \quad 0.0020$

$0.1212 \quad 0.0160$

$0.0607 \quad 0.0850$

$0.1409 \quad 0.2510$

$0.1292<0.001$

$0.2088 \quad 0.3820$

0.1668

Reliever Alone

Selectivity Adjusted NOT Adjusted

Parameter $\operatorname{Pr}>|\mathbf{t}| \quad$ Parameter $\operatorname{Pr}>|\mathbf{t}|$

Estimate

Estimate

$3.7828<0.001 \quad 4.5272<0.001$

$\begin{array}{llll}-0.0722 & 0.1220 & -0.0908 & 0.1640\end{array}$

$\begin{array}{llll}-0.0072 & 0.9330 & 0.0157 & 0.8020\end{array}$

$\begin{array}{llll}-0.2879<0.001 & -0.2616<0.001\end{array}$

$\begin{array}{llll}-0.0028 & 0.9630 & -0.0105 & 0.7990\end{array}$

$0.8801<0.001 \quad 0.7813<0.001$

$\begin{array}{llll}0.2532 & 0.0060 & 0.0820 & 0.2230\end{array}$

$\begin{array}{llll}0.0926 & 0.5090 & 0.0606 & 0.6120\end{array}$

$0.6096<0.001 \quad 0.5847<0.001$

$\begin{array}{llll}0.1177 & 0.0610 & 0.1100 & 0.0680\end{array}$

$\begin{array}{llll}-0.0919 & 0.0740 & -0.1036 & 0.0750\end{array}$

$\begin{array}{llll}0.1276 & 0.1330 & 0.2035 & 0.2150\end{array}$

$0.1871<0.001$

$0.1792<0.001$

$\begin{array}{llll}-0.2283 & 0.6180 & -0.1431 & 0.6050\end{array}$

$\begin{array}{llll}-0.0160 & 0.9720 & 0.0184 & 0.9440\end{array}$

$\begin{array}{llll}-0.0408 & 0.9310 & -0.0328 & 0.8990\end{array}$

$\begin{array}{llll}0.0865 & 0.8570 & 0.0843 & 0.7510\end{array}$

$-1.1454 \quad 0.4450$

$-3.9541<0.001$

$-1.9950<0.001$

0.3806

$-4.8800>0.999$

2881
0.3872

$3.3300 \quad 0.9997$

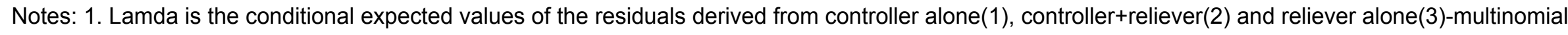
logit equation. 2. P-values are derived from bootstrapped standard errors. 
Figure 1. Controller/Reliever Medication Ratios by Plan Type and Year

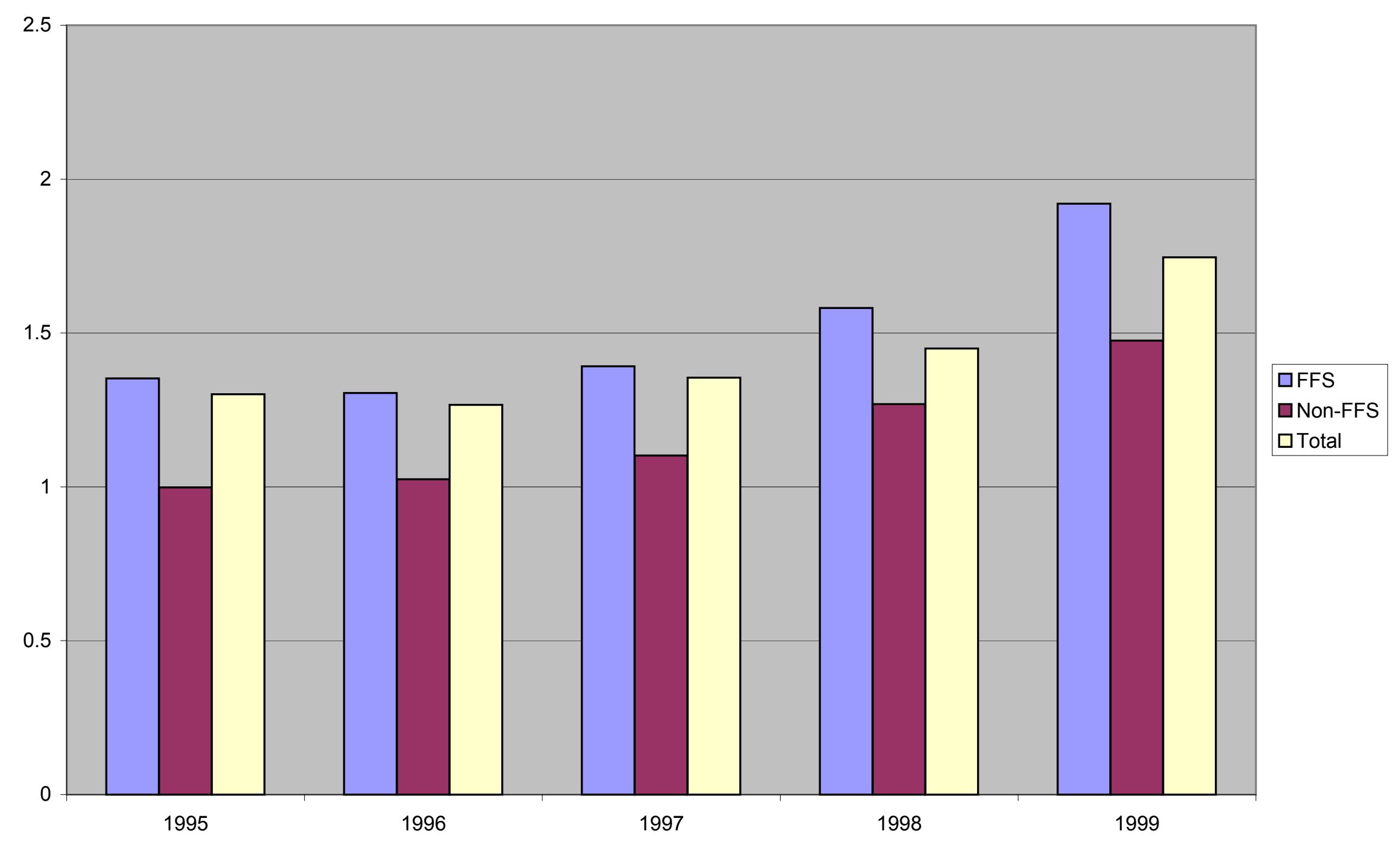


Figure 2. Controller/Reliever Copayment Ratios by Plan Type and Year

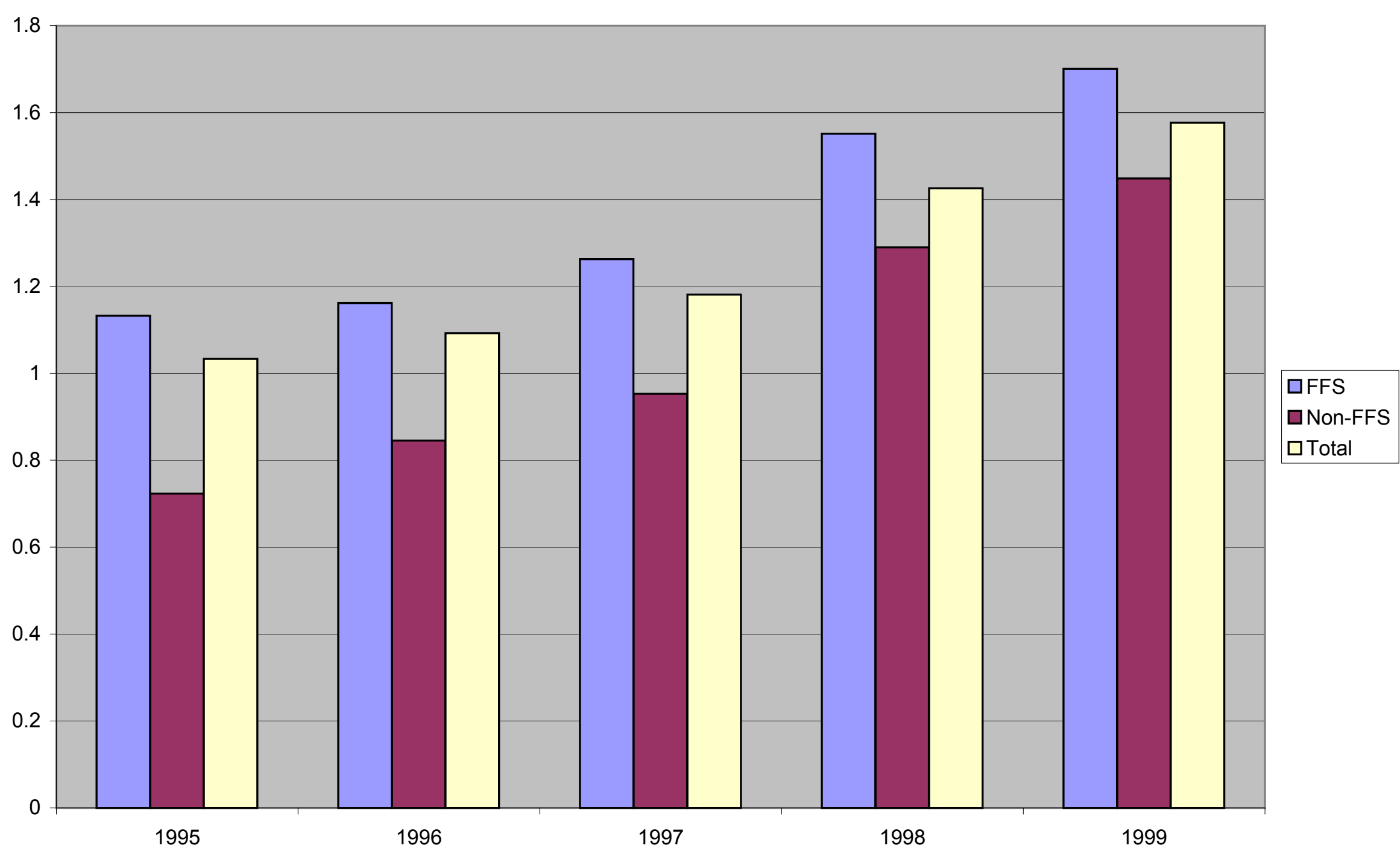


Figure 3. Trends in Asthma Medication Copayments by Plan Type

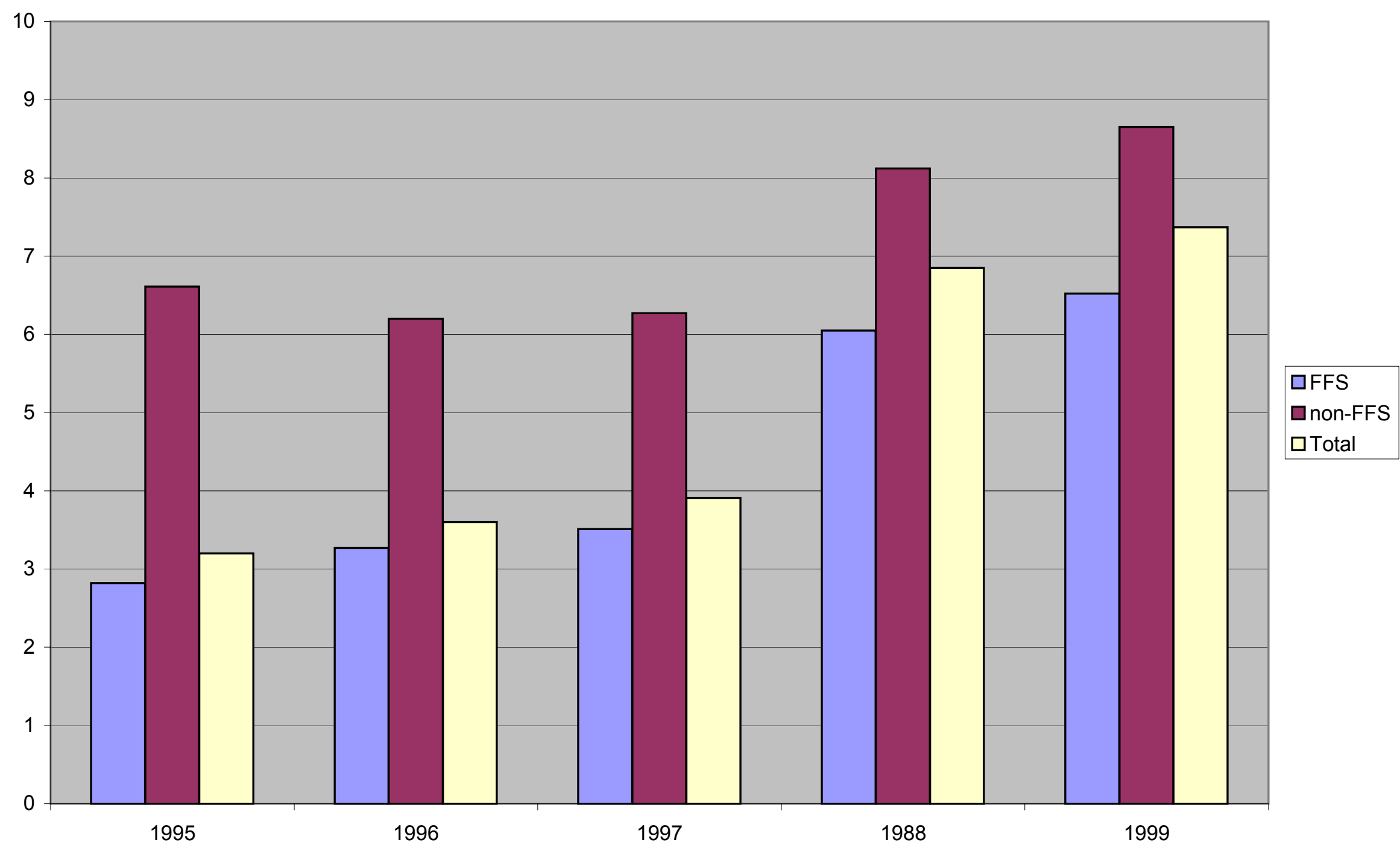


Figure 4. Trends in Total Payment Versus Copayment Ratios

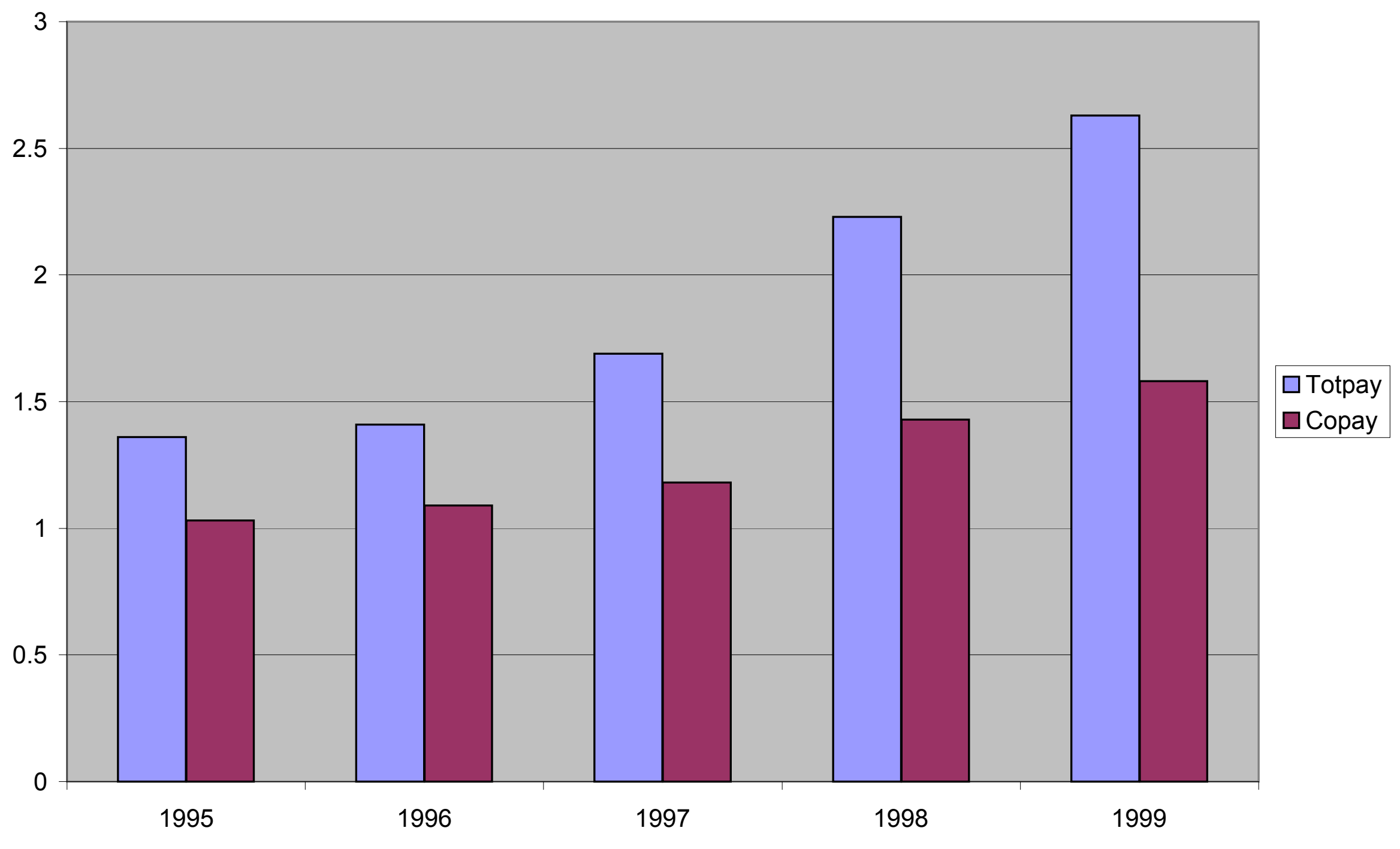

